\title{
Utilization of Biodiesel Wastes as a Bioresource for the Preparation of Activated Carbon
}

\author{
A. Buasri, N. Chaiyut, V. Loryuenyong, E. Phakdeepataraphan, S. Watpathomsub, \\ and V. Kunakemakorn, Member, IACSIT
}

\begin{abstract}
In this research, biodiesel wastes such as palm shells (PS) and Jatropha curcas fruit shells (JS) were used for the synthesis of activated carbon by chemical activation method using potassium hydroxide $(\mathrm{KOH})$ as an activating agent. The effects of acidic treatment in hydrofluoric acid (HF), impregnation ratio, activation temperature and activation time on the adsorption capacity of methylene blue (MB) and iodine $\left(I_{2}\right)$ solution were examined. The results showed that HF-treated activated carbons exhibited high adsorption capacities by eliminating ash residues, which might fill up the pores. In addition, the adsorption capacities of methylene blue and iodine solution were also significantly influenced by the types of raw materials, the activation temperature and the activation time. The highest adsorption capacity of methylene blue of $257.07 \mathrm{mg} / \mathrm{g}$ and iodine of $847.58 \mathrm{mg} / \mathrm{g}$ were obtained from Jatropha curcas wastes.
\end{abstract}

Index Terms-Activated carbon, biodiesel wastes, Jatropha curcas fruit shells (JS), palm shells (PS).

\section{INTRODUCTION}

Activated carbons were usually prepared from organic matter that consists of highly carbon. Agricultural wastes were one of interesting choices because it is low cost, renewable and abundant [1]-[3]. Palm shell (PS) and Jatropha curcas fruit shell (JS) contain low nutrient, which is not suitable for use as an agriculture fertilizer, but it is abundant in cellulose, hemicelluloses and lignin resulting in difficult to digest or degrade. Thus, a possible use of this waste is converting it into value-added activated carbon, which is one of the most widely used materials because of its exceptional adsorbent properties [4]-[6].

In general, the process for preparation of activated carbons involves two steps, carbonization of raw carbonaceous materials in an inert atmosphere followed by the activation of

Manuscript received January 27, 2013; revised March 27, 2013. This work was supported in part by the Department of Materials Science and Engineering, Faculty of Engineering and Industrial Technology, Silpakorn University.

Achanai Buasri, Nattawut Chaiyut, and Vorrada Loryuenyong are with the Department of Materials Science and Engineering, Faculty of Engineering and Industrial Technology, Silpakorn University, Nakhon Pathom 73000 Thailand and the National Center of Excellence for Petroleum, Petrochemicals and Advanced Materials, Chulalongkorn University, Bangkok 10330 Thailand (e-mail: achanai130@hotmail.com, nchaiyut@hotmail.com, vorrada@gmail.com).

Ekasit Phakdeepataraphan, Somchai Watpathomsub, and Vasin Kunakemakorn are undergraduate students in bachelor's degree program with the Department of Materials Science and Engineering, Faculty of Engineering and Industrial Technology, Silpakorn University, Nakhon Pathom $73000 \quad$ Thailand (e-mail: man.ekasit@gmail.com, senator0267@gmail.com, coaching_win@hotmail.com). the carbonized product. The activation process can be provided by two types, either by physical activation or chemical activation. However, chemical activation is now widely applied for the activation because of its lower activation temperature and higher product yield compared with the physical one [7].

The main objective of this work was to optimize the processes for the synthesis of activated carbon from biodiesel wastes (PS and JS) using carbonization and chemical activation method. $\mathrm{KOH}$ was used as an activating agent and the carbonization was performed under nitrogen atmosphere. The effects of acidic treatment in hydrofluoric acid (HF), impregnation ratio, activation temperature and activation time on adsorption capacity of methylene blue (MB) and iodine $\left(\mathrm{I}_{2}\right)$ solution are systematically investigated.

\section{EXPERIMENTAL METHODS}

\section{A. Materials and Preparation of Samples}

Agricultural wastes (PS and JS) were supplied by Research and Development Institute at Kamphaengsaen, Thailand. The starting materials were first cleaned with water and dried at room temperature for $24 \mathrm{~h}$. The dried samples were crushed with a blender and sieved to a size $600-1,000$ $\mu \mathrm{m}$. The dried sample was then impregnated in $\mathrm{KOH}$ solution (by weight ratio) at room temperature for $30 \mathrm{~min}$. After that, it was dried in a tube furnace at $150^{\circ} \mathrm{C}$ for $2 \mathrm{~h}$. The resulted sample was further activated in a tube furnace at fixed activation temperature and time. After cooling, the activated carbon was washed several times with hot distilled water until the $\mathrm{pH}$ became neutral. The washed sample was dried at $90^{\circ} \mathrm{C}$ for $24 \mathrm{~h}$ to obtain activated carbon of palm shells (ACPS) and Jatropha curcas fruit shells (ACJS). Then the obtained activated carbons were sieved to a size smaller than $150 \mu \mathrm{m}$ as the final product.

\section{B. Thermogravimetric Analysis (TGA)}

The pyrolysis behaviors of PS and JS were determined on a thermal analyzer (Perkin-Elmer, USA). 3-10 mg of sample material was heated from 50 to $8000 \mathrm{C}$ at a ramping rate of 10 $0 \mathrm{C} / \mathrm{min}$ under nitrogen gas atmosphere.

\section{Ash Content}

Ash contents were measured by combusting $5 \mathrm{~g}$ of raw materials in a muffle furnace at $800^{\circ} \mathrm{C}$ for $4 \mathrm{~h}$.

\section{Fourier Transform Infrared Spectroscopy (FT-IR)}

The physico-chemical characteristics of activated carbon produced by the optimum conditions in this experiment were 
determined. These surface functional groups were analyzed by using a FT-IR spectroscopy (Nicolet Impact 410). The activated carbon samples were mixed with potassium bromide $(\mathrm{KBr})$ and the mixture was pressed as a pellet prior to analysis. The IR spectrum was obtained at a resolution of 4 $\mathrm{cm}^{-1}$ over the range of $400-4,000 \mathrm{~cm}^{-1}$.

\section{E. Optimum Conditions for Synthesis of Activated Carbon}

Various parameters effecting activated carbon performance including acidic treatment, impregnation ratio of $\mathrm{KOH}$ to charcoal $(1: 1-2: 1 \mathrm{w} / \mathrm{w})$, activation temperature (700-900 0C) and activation time (0-120 min) were studied. In this work, efficiency and quality of the activated carbon were preliminarily characterized by measuring both iodine number and methylene blue number. Iodine number can be used for the estimation of the relative surface area and the measurement of porosity with the pores size greater than 1.0 $\mathrm{nm}$ in diameter. Methylene blue number, on the other hand, is one of the most widely recognized probe molecules for assessing the removal capacity of the specific carbon for moderate-size pollutant molecules $(\geq 1.5 \mathrm{~nm})$.

\section{F. Adsorption of Iodine and Methylene Blue}

The iodine number of activated carbon was obtained on the basis of the standard test method (ASTM D4607-94) by titration with sodium thiosulphate $\left(\mathrm{Na}_{2} \mathrm{~S}_{2} \mathrm{O}_{3}\right)$. The concentration of iodine solution was thus calculated from total volume of $\mathrm{Na}_{2} \mathrm{~S}_{2} \mathrm{O}_{3}$ used and volume dilution factor.

By batch experiment, methylene blue solution was mixed with activated carbon and stirred at room temperature in the place without light. After the completed reaction, the solutions were filtered and the concentrations of methylene blue solution were then determined by UV-Visible Spectrophotometer from Jasco V-350 at $664 \mathrm{~nm}$. The equilibrium adsorption capacities (Qe) of the activated carbon were determined based on adsorbate mass balance using (1).

$$
Q e=(C o-C e) V / M
$$

where $C o$ and $C e$ are the initial and equilibrium concentrations of the dye $(\mathrm{mg} / \mathrm{L})$, respectively. $\mathrm{V}$ is the volume of the aqueous solution (L) and $\mathrm{M}$ is the mass of activated carbon used (g).

\section{RESULTS AND DISCUSSION}

\section{A. Thermal Analysis of Materials}

Fig. 1 shows TGA graphs of PS. It was found that the first weight loss occurs at $50-100^{\circ} \mathrm{C}$ due to the elimination of moisture in the raw material. The large weight loss occurs at the temperature of $400^{\circ} \mathrm{C}$ due to the decomposition of the major components of lignocellulosic biomass including hemicellulose, cellulose and lignin. Lignin is generally the first component to decompose at a low temperature and low rate and continues on until approximately $900^{\circ} \mathrm{C}$. Hemicellulose is a light fraction component which also decomposes at the low temperature region between 200 and $360^{\circ} \mathrm{C}$. Cellulose is the last component to decompose at the high temperature range of $240-390^{\circ} \mathrm{C}$. At the temperatures above $400^{\circ} \mathrm{C}$, the final decomposition or weight loss involves the aromatization process of lignin fraction leading to very low weight loss [8]. Furthermore, it was found that the residual weight of PS treated in HF (B) is lower than that without HF treatment (A). This might be because HF removes the ash from the raw material [9], [10].

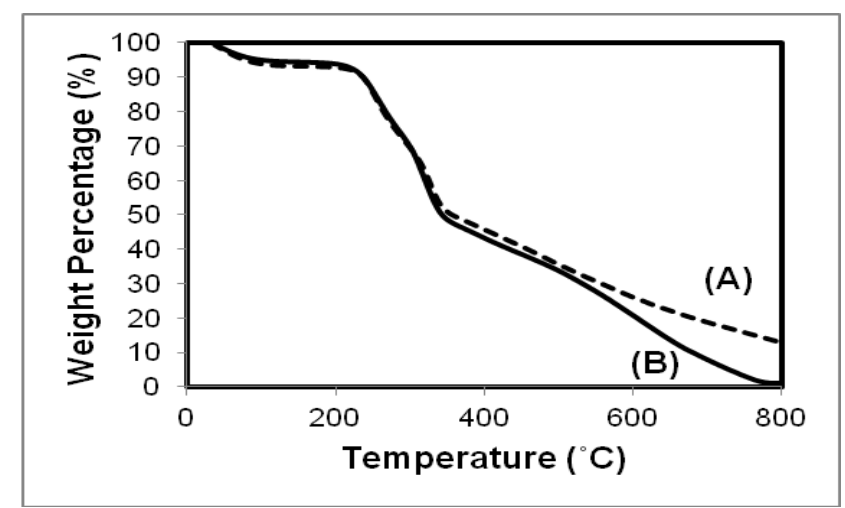

Fig. 1. Thermogram of materials (A) PS (B) PS soaked in HF.

Fig. 2 shows TGA graphs of JS. The first weight loss at 50-100 OC is observed due to the release of moisture in the raw material. At higher temperatures between $180-320^{\circ} \mathrm{C}$, a gradual weight loss is due to the thermal degradation of hemicellulose and cellulose. Moreover, this temperature also was an initial step for carbon structure formation. The last step of weight loss at $320-550^{\circ} \mathrm{C}$ indicates the thermal degradation of lignin. At the temperatures above $550^{\circ} \mathrm{C}$, no further weight loss is observed, indicating the formation of final carbon structures. Similar to PS, JS with HF soaking has lower remaining weight after heating to high temperatures.

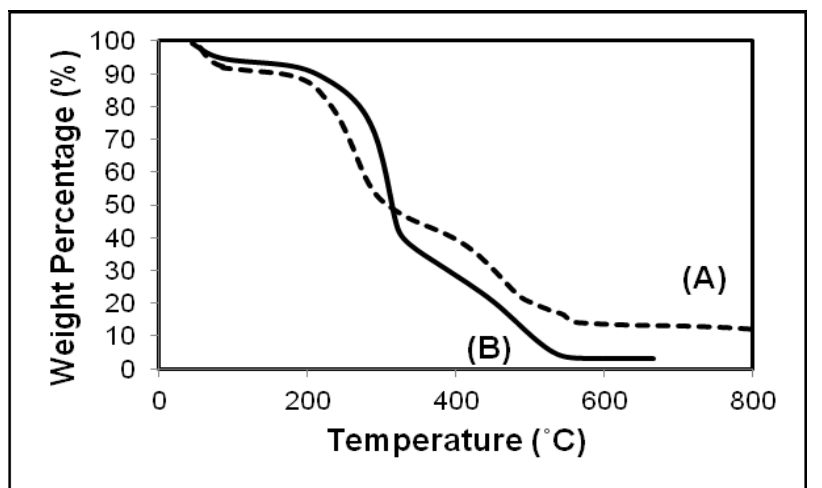

Fig. 2. Thermogram of materials (A) JS (B) JS soaked in HF.

\section{B. Ash Content of Materials}

To verify the ability of HF to remove the ash, both raw materials were combusted in a furnace at $8000 \mathrm{C}$ for $4 \mathrm{~h}$. The remaining ash contents are listed in Table I. From Table I, when soaked the raw materials in HF, the amount of ash in raw material was reducing. This confirms that $\mathrm{HF}$ can remove the ash that might block activated carbon's pore out of the raw material.

\section{Infrared Spectroscopy Analysis of Materials}

The FTIR spectra of the raw materials and activated carbons from PS (Fig. 3) and JS (Fig. 4) showed similar peaks. The peaks at 2923 and $2855 \mathrm{~cm}^{-1}$ are ascribed to C-H 
aliphatic stretching [5], [11]. Other important absorption peaks at $1022 \mathrm{~cm}^{-1}$ and $1100-1120 \mathrm{~cm}^{-1}$ represent C-O stretching [9], [12] and aromatic skeleton of lignin [13], respectively. Strong and broad peaks at $3300-3500 \mathrm{~cm}^{-1}$ correspond to $\mathrm{O}-\mathrm{H}$ stretching [14]. The peaks of symmetrical stretching of $\mathrm{C}=\mathrm{C}$ are also observed at $1600-1700 \mathrm{~cm}^{-1}$. There is another peak at $1385 \mathrm{~cm}^{-1}$ due to the presence of $-\mathrm{CH}_{3}$ stretching. It can be concluded that activation process decreased the lignin and aliphatic chain in the raw materials structure by thermal degradation, so the intensity of peak at 2923 and $2855 \mathrm{~cm}^{-1}, 1100-1120$ and $1022 \mathrm{~cm}^{-1}$ were decreased.

\begin{tabular}{ccccc}
\multicolumn{4}{c}{ TABLE I: AsH CONTENT IN RAW MATERIALS } \\
\hline \hline $\begin{array}{c}\text { Raw } \\
\text { materials }\end{array}$ & Ash weight $(\mathrm{g})$ & \multicolumn{2}{c}{ Ash content $(\%)$} \\
& Untreated & Treated & Untreated & Treated \\
\hline JS & 0.2506 & 0.2067 & 5.012 & 4.134 \\
PS & 0.2605 & 0.1042 & 5.21 & 2.084 \\
\hline \hline
\end{tabular}

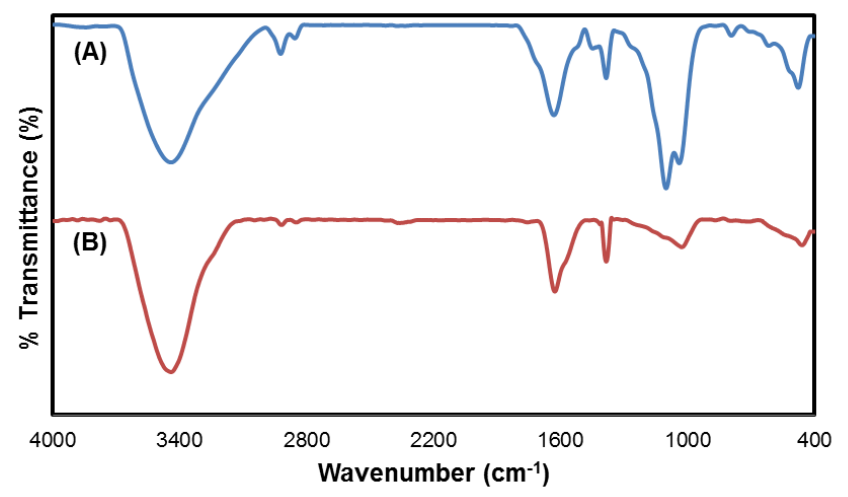

Fig. 3. IR-spectra of materials (A) PS (B) ACPS.

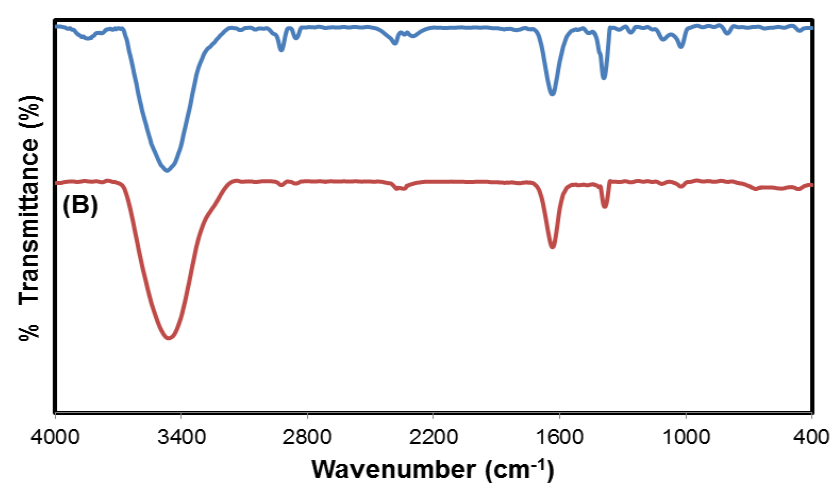

Fig. 4. IR-spectra of materials (A) JS (B) ACJS.

\section{Adsorption Capacity of Materials}

Fig. 5 shows the effects of HF treatment on adsorption capacity of activated carbon. It was found that activated carbons treated with HF have higher iodine and methylene blue adsorption capacities than those without HF treatment. Based on previous works, HF treatment could reduce ashes that clog up activated carbons' porosities [1], [9].

Fig. 6 shows the effects of impregnation ratio on adsorption capacity. For activated carbon from PS, both iodine number and methylene blue adsorption capacities were found to increase with increasing impregnation ratio. The higher impregnation ratio could result in an increasing possibility of reaction between activating agent and PS, and hence a larger amount of both micropores and mesopores [2], [3], [9], [15].

For activated carbon from JS, it was found that the optimal impregnation ratio with the highest iodine number and methylene blue adsorption capacity is equal to 1 and 1.5 , respectively. At higher values than 1 , the iodine number starts to decrease, and this might be due to lower surface area from the coalescence of micropores into mesopores [2], [6]. Similarly, for methylene blue adsorption capacity, too large impregnation ratio could induce mesopore widening, resulting in lower surface area [3].

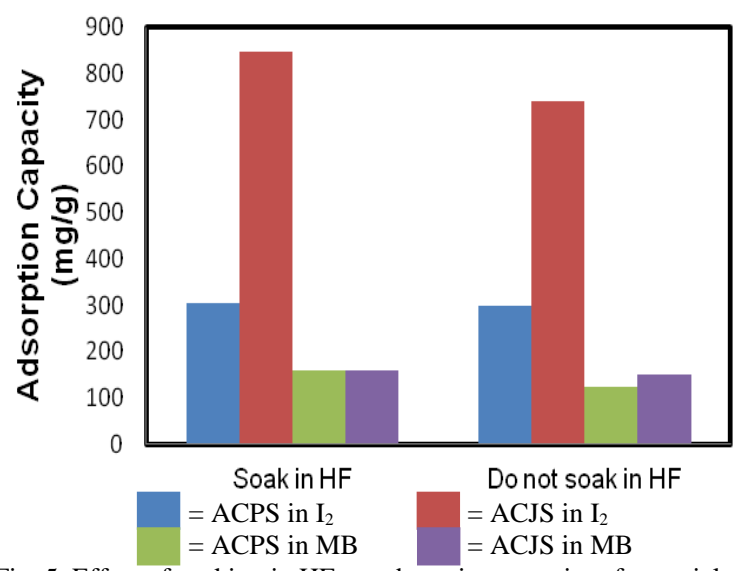

Fig. 5. Effect of soaking in HF on adsorption capacity of materials

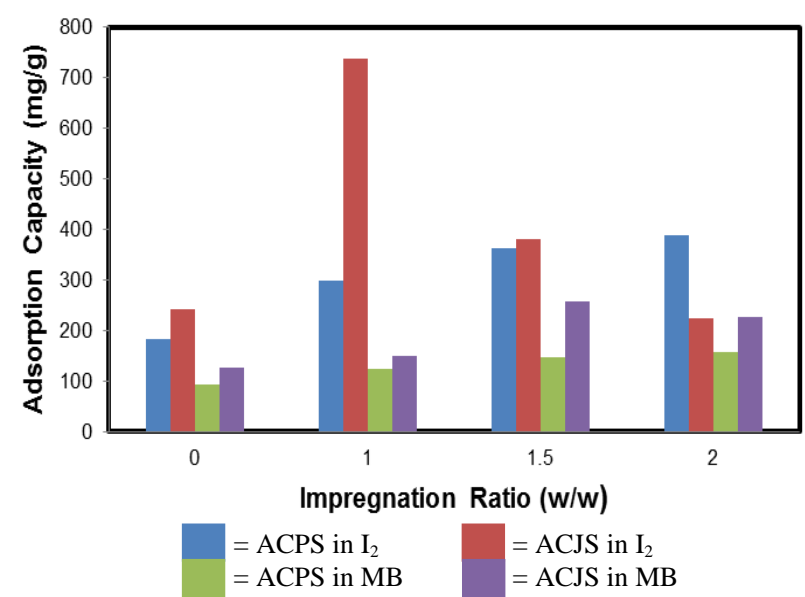

Fig. 6. Effect of impregnation ratio on adsorption capacity of materials.

Fig. 7 shows the effects of activation temperature on adsorption capacity. The iodine numbers of both raw materials decrease with increasing temperatures. This is due to the degradation of volatiles in the activated carbon, causing the micropores to be widened into larger pores [1], [16]. In contrast, for methylene blue adsorption capacity, some of micropores could be converted to mesopores at higher activation temperature, leading to an increase in methylene blue adsorption capacity [2], [9].

Fig. 8 shows the effects of activation time on adsorption capacity. The results of methylene blue adsorption test reveal an increase in adsorption capacity with increasing activation time. For the test of iodine number, it was found that increasing activation time reduces adsorption capacity in activated carbon from oil palm shell due to the pore widening effects. For activated carbon from JS, it was found that activation time of $1 \mathrm{~h}$ is the best time to maximize the iodine 
number. Longer reaction time could induce micropore to mesopore conversion, reducing the iodine number [16], [17].

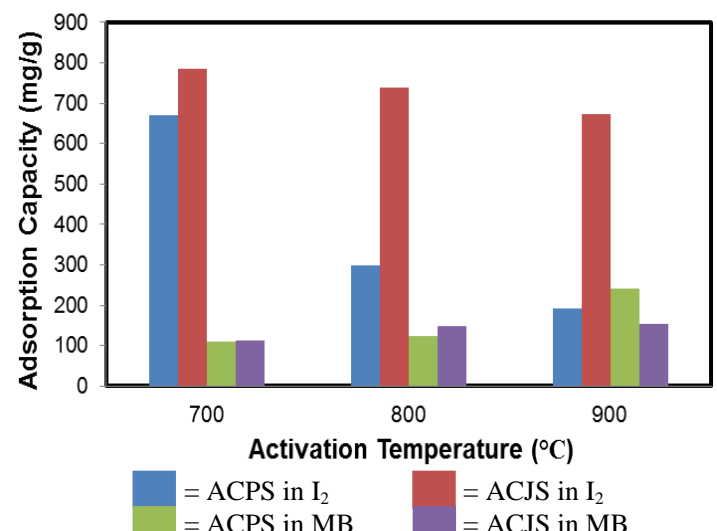

Fig. 7. Effect of activation temperature on adsorption capacity of materials.

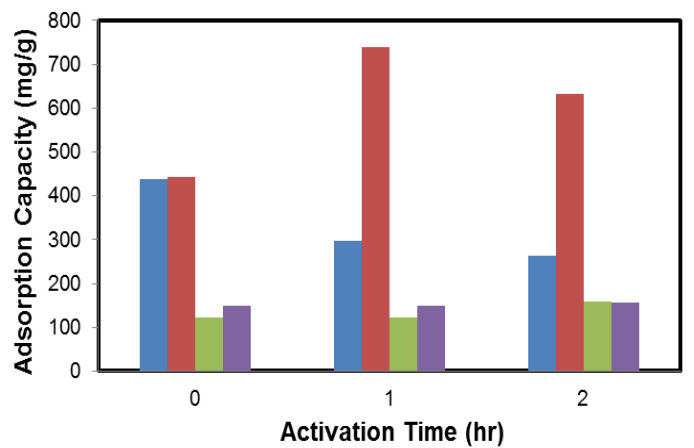

$\begin{array}{lll} & =\text { ACPS in } \mathrm{I}_{2} & =\text { ACJS in } \mathrm{I}_{2} \\ & =\text { ACPS in MB } & =\text { ACJS in MB }\end{array}$

Fig. 8. Effect of activation time on adsorption capacity of materials.

\section{CONCLUSION}

In summary, this research shows that biodiesel wastes could be effectively used for the preparation of activated carbons. The suitable conditions to achieve optimum iodine number for activated carbon from both PS and JS is $700^{\circ} \mathrm{C}$ activation temperature, $1 \mathrm{~h}$ activation time and $1: 1$ impregnation ratio. However, better adsorption capacity is obtained with HF soaking for JS and without HF soaking for PS.

\section{ACKNOWLEDGMENT}

The authors acknowledge sincerely the Department of Materials Science and Engineering (MSE), Faculty of Engineering and Industrial Technology, Silpakorn University (SU) and National Center of Excellence for Petroleum, Petrochemicals, and Advanced Materials (PPAM), Chulalongkorn University (CU) for supporting and encouraging this investigation.

\section{REFERENCES}

[1] Y. Sudaryanto, S. B. Hartono, W. Irawaty, H. Hindarso, and S. Ismadji, "High surface area activated carbon prepared from cassava peel by chemical activation," Bioresour. Technol., vol. 97, no. 5, pp. 734-739, 2006.

[2] D. Kalderis, S. Bethanis, P. Paraskeva, and E. Diamadopoulos, "Production of activated carbon from bagasse and rice husk by a single-stage chemical activation method at low retention times," Bioresour. Technol., vol. 99, no. 15, pp. 6809-6816, 2008.
[3] J. C. Moreno-Pirajan and L. Giraldo, "Study of activated carbons by pyrolysis of cassava peel in the presence of chloride zinc," J. Anal. Appl. Pyrolysis, vol. 87, no. 2, pp. 288-290, 2010.

[4] D. Adinata, W. M. Wan Daud, and M. K. Aroua, "Preparation and characterization of activated carbon from palm shell by chemical activation with $\mathrm{K}_{2} \mathrm{CO}_{3}$," Bioresour. Technol., vol. 98, no. 1, pp. 145-149, 2007.

[5] D. A. Z. Wever, H. J. Heeres, and A. A. Broekhuis, "Characterization of physic nut (Jatropha curcas L.) shells," Biomass Bioenerg., vol. 37, pp. 177-187, 2012.

[6] A. W. M. Ip, J. P. Barford, and G. McKay, "Production and comparison of high surface area bamboo derived active carbons," Bioresour Technol., vol. 99, no. 18, pp. 8909-8916, 2008.

[7] V. Fierro, G. Muñiz, A. H. Basta, H. El-Saied, and A. Celzard, "Rice straw as precursor of activated carbons: Activation with ortho-phosphoric acid," J. Hazard. Mater., vol. 181, pp. 27-34, 2010.

[8] P. Luangkiattikhun, C. Tangsathitkulchai, and M. Tangsathitkulchai, "Non-isothermal thermogravimetric analysis of oil-palm solid wastes," Bioresour. Technol., vol. 99, no. 5, pp. 986-997, 2008.

[9] W. Tongpoothorn, M. Sriuttha, P. Homchan, S. Chanthai, and C. Ruangviriyachai, "Preparation of activated carbon derived from Jatropha curcas fruit shell by simple thermo-chemical activation and characterization of their physico-chemical properties," Chem. Eng. Res. Des., vol. 89, no. 3, pp. 335-340, 2011.

[10] V. Sricharoenchaikul and D. Atong, "Thermal decomposition study on Jatropha curcas L. waste using TGA and fixed bed reactor," J. Anal. Appl. Pyrolysis, vol. 85, pp. 155-162, 2009.

[11] J. Guo and A. C. Lua, "Textural and chemical characterizations of adsorbent prepared from palm shell by potassium hydroxide impregnation at different stages," J. Colloid Interf. Sci., vol. 254, no. 2 , pp. 227-233, 2002

[12] K. Y. Foo and B. H. Hameed, "Preparation of oil palm (Elaeis) empty fruit bunch activated carbon by microwave-assisted $\mathrm{KOH}$ activation fo the adsorption of methylene blue," Desalination, vol. 275, no. 1-3, pp. 302-305, 2011.

[13] A. L. Ahmad, M. M. Loh, and J. A. Aziz, "Preparation and characterization of activated carbon from oil palm wood and its evaluation on methylene blue adsorption," Dyes Pigments, vol. 75, no. 2, pp. 263-272, 2007.

[14] B. K. Hamad, A. M. Noor, A. R. Afida, and M. N. M. Asri, "High removal of 4-chloroguaiacol by high surface area of oil palm shell-activated carbon activated with $\mathrm{NaOH}$ from aqueous solution," Desalination, vol. 257, no. 1-3, pp. 1-7, 2010

[15] Y. Guo, S. Yang, K. Yu, J. Zhao, Z. Wang, and H. Xu, "The preparation and mechanism studies of rice husk based porous carbon," Mater. Chem. Phys., vol. 74, no. 3, pp. 320-323, 2002.

[16] Y. Li, X. Ding, Y. Guo, L. Wang, C. Rong, Y. Qu, X. Ma, and Z. Wang, "A simple and highly effective process for the preparation of activated carbons with high surface area," Mater. Chem. Phys., vol 127, pp. 495-500, 2011.

[17] F. Lian, B. Xing, and L. Zhu, "Comparative study on composition, structure, and adsorption behavior of activated carbons derived from different synthetic waste polymers," J. Colloid Interf. Sci., vol. 360, no. 2, pp. 725-730, 2011.

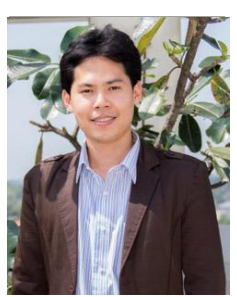

Achanai Buasri received his bachelor's degree in petrochemicals and polymeric materials from Silpakorn University, Thailand in 2002 and master's degree in chemical engineering from Chulalongkorn University, Thailand in 2004 . He is presently working as Assistant Professor in Department of Materials Science and Engineering, Faculty of Engineering and Industrial Technology, Silpakorn University, Thailand and joined institute in 2004. In addition, he is working as researcher in National Center of Excellence for Petroleum, Petrochemicals and Advanced Materials, Chulalongkorn University, Thailand. His main research interests are nanocomposite materials, renewable energy and wastewater treatment. This author became a Member of IACSIT.

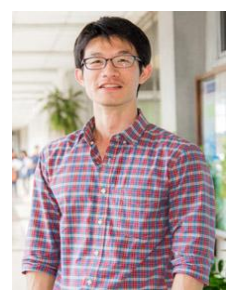

Nattawut Chaiyut received his bachelor's degree in petrochemicals and polymeric materials from Silpakorn University, Thailand in 1999 and doctor of philosophy (Ph.D.) degree in polymer science and technology from Mahidol University, Thailand in 2005. He is presently working as Lecturer in Department of Materials Science and Engineering, Faculty of Engineering and Industrial Technology, Silpakorn University, Thailand and joined institute in 
2004. In addition, he is working as researcher in National Center of Excellence for Petroleum, Petrochemicals and Advanced Materials, Chulalongkorn University, Thailand. His main research interests are biopolymers, polymer nanocomposites and polymer physics.

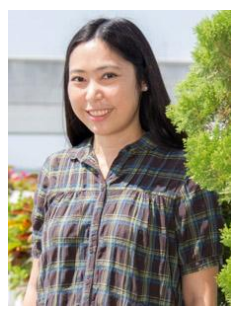

Vorrada Loryuenyong received her bachelor's degree in materials science and engineering from The Pennsylvania State University, USA in 2000, master's degree in materials science and engineering from University of California-Berkeley, USA in 2002 and doctor of philosophy (Ph.D.) degree in materials science and engineering from University of California-Berkeley, USA in 2006. She is presently working as Assistant Professor in Department of Materials Science and Engineering, Faculty of Engineering and Industrial Technology, Silpakorn University, Thailand and joined institute in 2006. In addition, she is working as researcher in National Center of Excellence for Petroleum, Petrochemicals and Advanced Materials, Chulalongkorn University, Thailand. Her main research interests are sol-gel process, semiconductor materials, thin film, photocatalysts and dye-sensitized solar cell (DSSC).

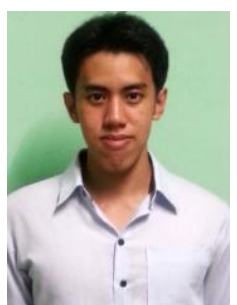

Ekasit Phakdeepataraphan is an undergraduate student in bachelor's degree program (petrochemicals and polymeric materials) with the Department of Materials Science and Engineering, Faculty of Engineering and Industrial Technology, Silpakorn University, Thailand.

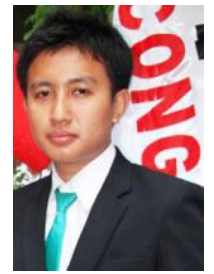

Somchai Watpathomsub is an undergraduate student in bachelor's degree program (petrochemicals and polymeric materials) with the Department of Materials Science and Engineering, Faculty of Engineering and Industrial Technology, Silpakorn University, Thailand.

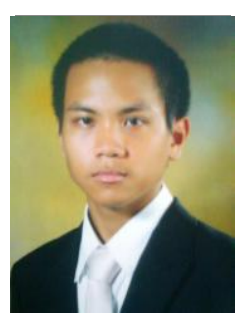

Vasin Kunakemakorn is an undergraduate student in bachelor's degree program (petrochemicals and polymeric materials) with the Department of Materials Science and Engineering, Faculty of Engineering and Industrial Technology, Silpakorn University, Thailand. 